\title{
Productive flows control in coal mines under the condition of diversification of production
}

\author{
Oleksandr Mamaikin ${ }^{1 *}$, Vadym Sotskov ${ }^{1}$, Yurii Demchenko ${ }^{1}$, and Oleksandr Prykhorchuk ${ }^{2}$ \\ ${ }^{1}$ National Mining University, Department of Underground Mining, 19 Yavornytskoho Ave., \\ 49005 Dnipro, Ukraine \\ ${ }^{2}$ PJSC "DTEK Pavlogradvuhillia", MA "Pershotravenske", 76 Soborna Ave., 51400 Pavlohrad, \\ Ukraine
}

\begin{abstract}
The objective of the work consists in methodical bases of concept development for control by productive flows in coal mines with the use of cost-effective mechanisms. These mechanisms would provide their stable functioning in conditions of uncertainty and risks, formed by internal and external factors. The theoretic views have been used for the supply system structuring, when assessing the opportunities and reasonability to contract out the diversified production operations. The correlation of industrial factors has been defined, representing the mine as a multi-level system, and a logical interpretation of the obtained dependences. The system of efficiency evaluation has been proposed, which is intended to supplement the existing system of risk management with a kind of control element, an indicator of the positive processes in processing technogenic wastes of mines and dressing plants.
\end{abstract}

\section{Setting the problem in general terms and its connection with important scientific and practical tasks}

The result of the production activity of the underground complex of mining operations is the production on the surface of four productive components, which from the viewpoint of rational resource and nature management can be considered on the one hand, as factors that can have a negative impact on the environment. These components are: coal, rock, mine water and pit gas $[1,2]$. Considering their dynamic nature, it is expedient for the mathematical description of moving processes of coal $(C)$, rock $(R)$, pit gas $(G)$ and water $(W)$ to present them as flows in some technological system of converters. In such a case, the aim of conversion is to obtain basic and additional resources of raw materials, as well as environmental damage minimization. At the same time, the degree of the impact of coal mining enterprise on the environment, on the one hand, is determined by the efficiency of each production unit included in it. On the other hand, it is determined by the mutual coordination of the objectives of all the production units that contribute to achieving the overall objectives of the enterprise. That is, for coal mines, which differ in the specific of the natural component effect, the possibilities of achieving the common goals represent the sum of local opportunities to achieve goals by all production units with the condition of

\footnotetext{
*Corresponding author: mamaykin@yahoo.com
} 
minimizing the environmental footprint $(F)$.

$$
F=C+R+G+W \rightarrow \min .
$$

As can be seen in the expression (1), all components are positive, then minimization of the sum means minimization of each summand. The minimization of the first summand $C$ is equivalent to the decrease in ash content and damage from surface underworking to the minimum permissible value. The minimization of the second summand $R$ means the maximum volume of rock left in the mine and its use as an object of production diversification. In particular, if the entire rock is not released to the surface, $R$ takes on its minimum value equal to zero. The minimization of the third summand $G$ leads to reduction of methane emissions into the atmosphere, and minimization of the parameter $W$ values leads to a decrease in the volume of release into the environment of highly mineralized mine water.

All the summands in the expression (1) are unrelated and their minimization represents, in a number of cases, contradictory tendencies. Therefore, the comparative value of the coefficients in the objective function should reflect the balance of these contradictory tendencies impact [3].

For any coal mining enterprise, the most desirable is the economic situation, at which the full predictability of its development is achieved in all directions, both external and internal. Under these conditions, the planned volume of marketable products, sold in the energy market is easyly produced. Reserves are prepared for extraction without any obstacles, productivity increases within a predetermined range, and as a major result of its productive and economic activity, the mine receives a profit in that amount, which satisfies its interests to the fullest extent [4-6].

A review of the theoretical views of individual scientists has shown that the structuring of the supply system becomes a very important factor in assessing the opportunities and reasonability to contract out the diversified production operations [7]. For each enterprise, the consequences of making a decision to implement a contract form of work organization cannot be the same, and if so, they should be different in weight and value. So, it is necessary to weigh carefully all the pros and cons, as well as to consider other possibilities for the use of rock, gas or mine water.

\section{Presentation of the main research material with full substantiation of scientific results obtained}

Obviously, it is desirable to allocate capital investments for the development of mines, where the greatest effect is expected. Difficulty in determining such mines (and their sequence) is due to the complexity of the mine as a natural-technological system [8]. The results of the mine operation depend on a wide range of factors, which act strictly individually in the specific conditions of each mine and often have the opposite direction. For example, the mine may have a relatively shallow depth of development, but also a low thickness of a seam $[9,10]$. Natural factors exist from time eternal, they are not controlled and their effect is largely predictable. Industrial factors - machinery, technology, organization of production - in principle are controlled, but often influenced by natural factors and their changes, and are usually associated with high costs [11].

Industrial factors, which describe the mine as a multi-level system, are quite varied and not always adequately describe the state of the system both qualitatively and quantitatively. The requirements for choice of the most specific factors and those, which make it possible to differentiate one enterprise from another, can be the following:

- indicators of the state of the mine are of significant importance - its prospects, the complexity of the production system, the situation (in terms of the enterprise capacity) 
among other mines, the ratio of mine production processes;

- it is desirable that the number of factors taken into account was not too large, they should be quite clear in their content and obtained in the simplest way from the materials of the current reporting.

In our opinion, such factors may be the annual production $(D)$, level of concentration of work $(K)$, producing cost $(S)$, and labor productivity of a mining worker $(P)$. These parameters describe the coal mining enterprise not only as technical and economic indicators, but they give the chance to estimate the unused internal reserves to increase or improve the production state, or for calculations to substantiate the need for diversification at the best case with the subsequent prospect of closure and total liquidation.

Identifying the relationship of these factors to each other and the logical interpretation of the dependencies obtained can provide an answer to one of the main issues of the future fate of the domestic coal industry in general and specific enterprises related to each other by identical geological and geological conditions, territorially and socially.

In the market interpretation, with an increase in the labor productivity and the level of concentration of work, the producing cost should decrease. By increasing the length of the face line, (and this is an indicator of the growth in the deconcentration of work), the producing cost should increase. These assumptions have been tested in the analysis of the work of 10 mines in the Selidovo and Mirgorodsk districts. Linear relationships between producing costs and parameters $P, K$, and $D$ have been constructed with the aim of subsequent construction of linear optimization models. Static totality was quite indicative, as confirmed by the relevant fitting criterion (a period of 10 years was considered - from 2007 to 2016).

The results of calculations of multiple regressions are given in Table 1, and in Table 2 the corresponding equations of net regression. Noteworthy is the fact that in some mines, with an increase in labor productivity, the producing cost rises [12, 13]. This can be interpreted as nonsense, although this phenomenon can be explained, as well as the growth of producing costs while increasing production in mine.

In connection with an improper tendency of the interrelation between the producing costs and the argument factors, it follows that the data are discrepant and can not be the basis as coefficients for unknown variables in constructing a complex model of the mines parameters optimization.

The main reason for the inadequacy of the obtained results is in the inconsistency of the applied technologies to modern trends or in the unreliable technical and economic performance indicators of enterprises over recent years, especially with the introduction of such term as "commercial confidentiality".

Table 1. The equation of multiple regression in the mines of Myrnohradskyi and Selidovskyi districts.

\begin{tabular}{|c|c|c|c|}
\hline \multirow[b]{2}{*}{ Mine } & \multicolumn{3}{|c|}{ The dependence of the producing costs $(S)$ from } \\
\hline & $\begin{array}{c}\text { labor productivity of a } \\
\text { worker in production }(P), \\
\mathrm{t} / \text { month }\end{array}$ & $\begin{array}{l}\text { the actual extraction } \\
\text { of the mine }(D), \\
\mathrm{m} / \text { month }\end{array}$ & $\begin{array}{l}\text { the level of work } \\
\text { concentration in } \\
\text { mine }(K), \mathrm{m} / 1000 \mathrm{t}\end{array}$ \\
\hline Stakhanova & \multicolumn{3}{|c|}{$S=2655.9-24.1 P-0.1 D-3.9 K$} \\
\hline Kotliarevska & \multicolumn{3}{|c|}{$S=989.2+70.9 P-5.2 D+2.6 K$} \\
\hline Kurakhivska & \multicolumn{3}{|c|}{$S=5461.2-239.9 P+221.6 D+0.87 K$} \\
\hline Rodinska & \multicolumn{3}{|c|}{$S=1930.8-4.7 P-6.6 D+4.1 K$} \\
\hline Yuzhnodonbaska No. 1 & \multicolumn{3}{|c|}{$S=1095.2+31.5 P-1.9 D+2.6 K$} \\
\hline Yuzhnodonbaska No. 3 & \multicolumn{3}{|c|}{$S=4582.5+23.6 P-2.9 D-4.5 K$} \\
\hline 1-3 Novohrodivska & \multicolumn{3}{|c|}{$S=5331.8-42 P-2.1 D-4.9 K$} \\
\hline Ukraine & \multicolumn{3}{|c|}{$S=4383.4-126.4 P+8.1 D+0.4 K$} \\
\hline Tsentralna & \multicolumn{3}{|c|}{$S=3169.4+17.8 P-9.6 D-0.5 K$} \\
\hline Mine $5 / 6$ & \multicolumn{3}{|c|}{$S=-1428.7+86.8 P-11.8 D+5.3 K$} \\
\hline
\end{tabular}


Table 2. The equation of net regression in the mines of Myrnohradskyi and Selidovskyi districts.

\begin{tabular}{|l|l|l|l|}
\hline \multirow{2}{*}{ Mine } & \multicolumn{3}{|c|}{ The dependence of the producing costs $(S)$ from } \\
\cline { 2 - 4 } & $\begin{array}{c}\text { labor productivity of a } \\
\text { worker in production } \\
(P), \mathrm{t} / \text { month. }\end{array}$ & $\begin{array}{c}\text { the actual extraction } \\
\text { of the mine }(D), \\
\text { m/month. }\end{array}$ & $\begin{array}{c}\text { the level of work } \\
\text { concentration in } \\
\text { mine }(K), \mathrm{m} / 1000 \mathrm{t}\end{array}$ \\
\hline Stakhanova & $S=2409.5-38.8 P$ & $S=2343.7-2.3 D$ & $S=1998.2-5.7 \mathrm{~K}$ \\
\hline Kotliarevska & $S=2275.1-30.8 P$ & $S=2570.3-2.1 D$ & $S=118.9+2.6 \mathrm{~K}$ \\
\hline Kurakhivska & $S=4577.8-90.1 P$ & $S=3408.8-10.5 D$ & $S=-2328.5-1.7 \mathrm{~K}$ \\
\hline Rodinska & $S=3997.2-76.9 P$ & $S=3728.9-18.3 \mathrm{D}$ & $S=742.0+6.5 \mathrm{~K}$ \\
\hline Yuzhnodonbaska No. 1 & $S=2239.2-27.8 P$ & $S=2559.9-1.9 D$ & $S=-703.8+8.1 \mathrm{~K}$ \\
\hline Yuzhnodonbaska No. 3 & $S=1272.2-5.2 P$ & $S=2194.6-1.3 D$ & $S=2899.1-4.6 \mathrm{~K}$ \\
\hline 1-3 Novohrodivska & $S=3081.5-41.8 P$ & $S=2186.7-3.2 D$ & $S=581.1+1.9 \mathrm{~K}$ \\
\hline Ukraine & $S=3403.8-26.5 P$ & $S=2876.4-4.1 D$ & $S=2357.1+0.2 \mathrm{~K}$ \\
\hline Tsentralna & $S=2557.6-30.5 P$ & $S=1884.5-1.1 D$ & $S=1745.4-1.2 \mathrm{~K}$ \\
\hline Mine 5/6 & $S=1398.3+12.2 P$ & $S=3115.3-10.6 D$ & $S=-452.8+4.9 \mathrm{~K}$ \\
\hline
\end{tabular}

But the limited size of mine fields $(1000-1500 \mathrm{~m})$ as compared to $2000-3000 \mathrm{~m}$ in other countries, provides evidenced both of the insufficient level of planning decisions and the insufficient energy saturation and reliability of extracting machines.

The amount of comprehensive faces, working with a low load (less than 500 tons/day), is $65 \%$.

The most important is to solve the issues related not only to changes in coal mining technology in enterprises, which, ipso facto, have the internal reserves to increase labor productivity, but also involvement in this not simple process of low-potential coal-mining enterprises with low profitability or working with low productivity caused by objective circumstances.

Modern trends in the coal industry maintenance are intimately connected with the diversification of mining enterprises (see Fig. 1). One of the most promising trend is the maintenance of capacity of mines, primarily unprofitable ones, in the direction of advanced processing of coal, coalmine methane and coal waste at the place of their extraction through the production of thermal and electric energy, the introduction of highly efficient waste processing technologies, etc. $[14,15]$. This will change the price of the final product structure, where the producing cost of coal will no longer play a decisive role, and will be one of the components.

There are more than 1.500 dumps in the Donbas territory, and in each of them there is an average of 1.144 cubic meters of rock. They extend for significant areas and have a negative impact on the atmosphere, soils, surface and underground water sources. Therefore, the problem of dumps recycling is urgent at the moment [16-18]. There are proposed more and more projects, according to which mini-factories for the extraction of coal and strategically important aluminum, germanium, scandium, gallium, yttrium and even zirconium, can be built on the basis of the closed mines. With the help of advanced technologies, a whole range of problems can be solved: environmental (in relation to mine communities), social (new jobs), land (the release of territories for construction). Moreover, the raw material received from one average volume of a dump costs at least $\$ 100$ million dollars, since the presence in mines of industrial infrastructure will reduce the costs and implementation deadline of the planned production. The proposed projects emphasize the need for about 5 million dollars to equip the complex processing of refuse ore with smelting furnaces and electrohydraulic crushers, as well as about the same amount for the purchase of chemical reagents.

In a similar way it can be considered, from the perspective of the mine potential level (EVA), the reasonability of involving into mining the worst reserves, which, in the form of 
complex mining and geological conditions and the conditioning reserves depletion, are obviously unprofitable in the sale of coal at existing wholesale prices (2). Obviously, the question arises on the reasonability of involving into mining of complex reserves of deeply unprofitable mines. Despite the fact that the involvement for mining of these areas of the mine field leads to increased loss, the final decision depends on the adopted system of government subsidies to such enterprises. If the subsidy is payed in the fixed form, then it is not profitable for the enterprise to involve a complex area for mining, since in this case, without any effort on its part, the mine assumes a more favorable position when refusing complex reserves mining.

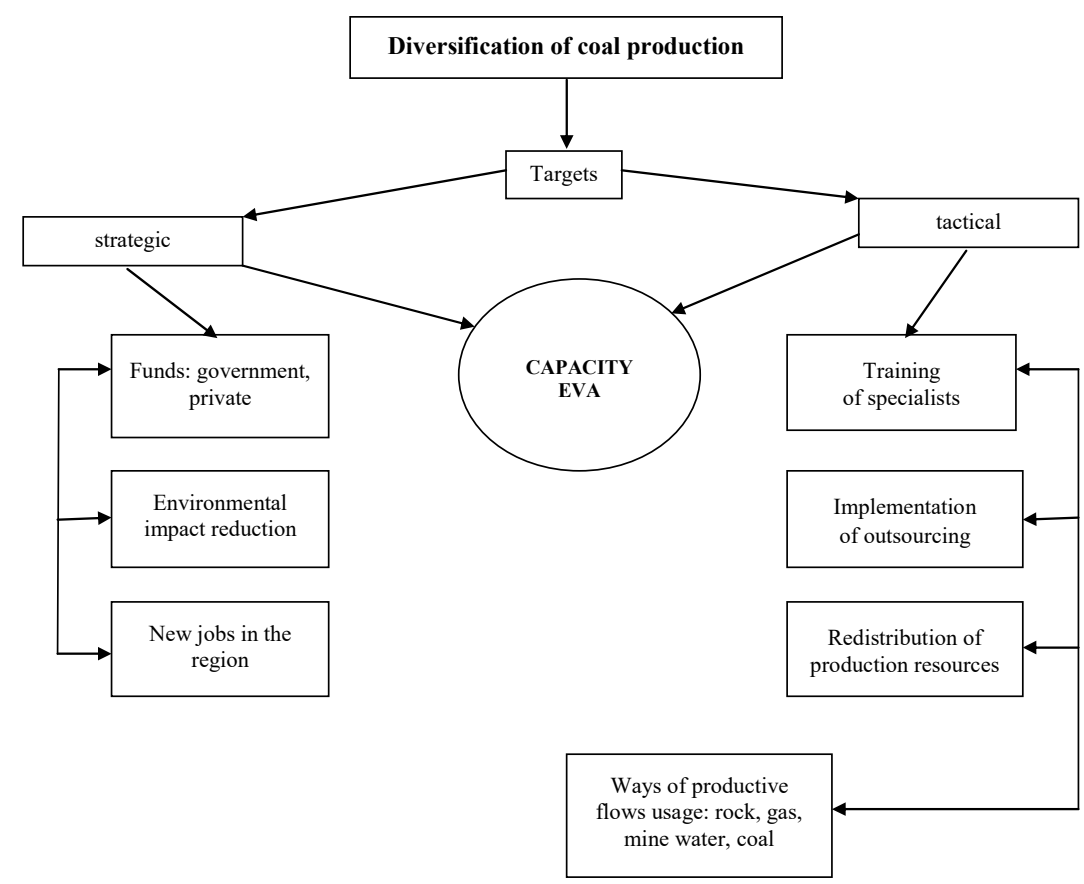

Fig. 1. Tactical and strategic features of production diversification.

With the help of relevant indicators, the capabilities of selected outsourcers are compared, and the feasibility of the contract form or the feasibility of a separate enterprise establishment for the production of diversified production on the basis of existing divisions, are analysed. Mathematically, the indicators are as follows: $T_{i}$ - annual coal production from the dumps dismantling; $W_{i}$ - energy, obtained from water use $i$-th mine in thermal pumps; $B_{l}$ - volume of ceramic products from rocks $l$-th dump; $R_{l}$ - volume of building materials after dismantling $l$-th dump for road construction.

$$
E V A(\max )=\left\{\begin{array}{l}
P(T, W, B, R), \text { if } \lambda \geq 1 ; \\
P(T, W, B, R)+S_{i}, \text { if } 1 \geq \lambda \leq 0.5 ; \\
S_{i}, \text { if } \lambda \leq 0.5,
\end{array}\right.
$$

where $P(T, W, B, R)$ is the only outsourcing services; $\lambda$ is the relative evaluation for each type of outsourcing services in the market of waste recycling; $S_{i}$ is the services of the $i$-th type by own divisions. 
The determination of the criteria weight in each of the cases is carried out on the basis of the expert assessments method. The overall assessment of the possibilities of the contract application $P(T, W, B, R)$, or independent performance of these works $S_{i}$, is calculated as the sum of all criteria values with regard to their weight. Since the capabilities of outsourcers are evaluated by several independent indicators, therefore, the choice can be made based on the principle of minimax (maximin). At the same time, the optimal alternative is the alternative, which is not worse by all indicators and better, at least, by one indicator.

When assessing the consequences of diversified enterprises creation, a clearly expressed problem of uncertainty is possible. Uncertainty is understood to be the incompleteness and (or) inaccuracy of information on the conditions for the diversified products realization, including the necessary costs and expected results. The uncertainty associated with the possibility of the adverse situations emergence and consequences is characterized by the concept of risk. When managing the processes of diversified coal enterprises support, both objective and forecast uncertainties must be considered. The probability of the latter one is greater, because it is associated with changes in market conditions, prices, subsidy policy, etc. Since all of these factors can not be completely overcome, hence the nature of the risks at the stage of new companies' privatization, the change of ownership, change of resource potential. Basically, the management by sustainable development and costs, anyhow, implies the use of two criteria - the maximum production with the given capabilities of the resource potential and the minimum production costs. The value of both functionals is important for the manager. If they are significantly different, it is necessary to apply mathematical techniques associated with decision-making under uncertainty. Unfortunately, there are no general rules for assessing the applicability of a criterion, since the behavior (often changing) of an investor who makes a decision due to the uncertainty of the situation, is the most important factor in choosing the appropriate criterion.

It is known that coal-mining enterprises (mainly unprofitable) are transformed to new conditions with difficulty, and to some extent, they restrain the course of market reforms in the country $[19,20]$. But backlog, in particular, such as the diversification of coal production, can be explained, above all, by the fact that the economic mechanism for regulation of the enterprises capacity in a particular region has not been worked out, rather than by the lack of experience. The system of efficiency evaluation has been proposed, which is intended to supplement the existing system of risk management with a kind of control element, an indicator of the positive processes in processing technogenic wastes of mines and dressing plants.

\section{Conclusions}

Based on the definition, diversification can be characterized as subsidiary production with its own divisions. Therefore, an assumption can be made regarding performance by them of service functions, that is, services, provision of services, and thus, their involvement into the service sector.

The supply system structuring is relevant to the rendering of service functions of the coal company outside the enterprise, if they are organized in the form of subsidiary facilities. The main production regulates the demand and distributes it among the divisions. Even the service divisions themselves can act as economic participants and be closely interrelated, such as the introduction of thermal pumps for heating the housing or extracting coal from the dump.

The possibility of a significant reduction in costs by eliminating unprofitable sites and subdivisions engaged in secondary, periodically performed work on environmental protection, processing of rock, etc., facilitates the development of outsourcing in the coalmining regions. An important aspect of the advantages of outsourcing is the use of special 
production, technological and laboratory equipment, storage facilities, vehicles and construction mechanisms.

The research is carried out within the framework of scientific topics "Resource-saving geotechnical and hydrodynamic parametrization of the extraction of low-capacity mineral raw materials in an technogenically loaded environment" (State registration No. 0117U006753), financed by the state budget of Ukraine.

\section{References}

1. Mamaikin, O., Kicki, J., Salli, S., \& Horbatova, V. (2017). Coal industry in the context of Ukraine economic security. Mining of Mineral Deposits, 11(1), 17-22. https://doi.org/10.15407/mining11.01.017

2. Mamaikin, O.R., Salli, S.V., Pochepov, V.M., \& Ashcheulova, O.M. (2015). Complex assessment of the recovery ratio of unprofitable mines. Mining of Mineral Deposits, 9(1), 135139. https://doi.org/10.15407/mining09.01.135

3. Coyle, E.D., \& Simmons, R.A. (2014). Understanding the global energy crisis. Purdue University Press.

4. Vermeylen, K. (2015). The Stochastic Growth Model. BookBoon.

5. Opara, V., Buzina, I., \& Vynohradenko, S. (2017). Environmental-economic efficiency of land use improvement reasoning. Visnyk of V.N Karazin Kharkiv national university-series geology geography ecology, (46), 152-157. https://doi.org/10.26565/2410-7360-2017-46-21

6. Minke, A.G. (2013). Conducting transatlantic business: Basic legal distinctions in the US and Europe. BookBoon, 59.

7. Mazzeo, N. (2013). Chemistry, emission control, radioactive pollution and indoor air quality. InTech.

8. Fomichov, V., Sotskov, V., \& Malykhin, A. (2014). Determination and analysis of the acceptable benchmark changes of the stress strain state of frame and bolt fastening elements of dismantling drift when approaching a working face. Naukovyi Visnyk Natsionalnoho Hirnychoho Universytetu, (1), 22-26.

9. Sotskov, V.O., Demchenko, Yu.I., Salli, S.V. \& Dereviahina, N.I (2017). Optimization parameters of overworked mining gallery's support during carrying out long-wall face workings. Naukovyi Visnyk Natsionalnoho Hirnychoho Universytetu, (6), 34-40.

10. Kovalevska, I., Barabash, M., \& Snihur, V. (2018). Development of a research methodology and analysis of the stress state of a parting under the joint and downward mining of coal seams. Mining of Mineral Deposits, 12(1), 76-84. https://doi.org/10.15407/mining12.01.076

11. Sotskov, V., \& Saleev, I. (2013). Investigation of the rock massif stress strain state in conditions of the drainage drift overworking. Mining of Mineral Deposits, 197-202. https://doi.org/10.1201/b16354-36

12. Bai, J., Ghysels, E., \& Wright, J. (2013). State space models and MIDAS regressions. Econometric Reviews, (32), 779-813.

13. Goncalves, S. \& Perron, B. (2017). Tests of equal accuracy for nested models with estimated factors. Journal of Econometrics, 198(2), 231-252.

14. Clark, T.E., \& McCracken, M.W. (2017). Tests of predictive ability for vector autoregressions used for conditional forecasting. Journal of Applied Econometrics, (32), 533-553.

15. Sadovenko, I.O., Zahrytsenko, A.M., Podvihina, O.O. \& Dereviahina, N.I. (2017). Water balance control within rock mass using the capacity of water-bearing formations. Scientific Bulletin of National Mining University. (4), 19-26.

16. Demchenko, O., Evtekhov, V., Evtekhova, A., \& Georgiieva, H. (2018). Grounding for effective technology of reprocessing coarse grained screenings from crushing and screening plants of Kryvyi Rih basin. Visnyk of Taras Shevchenko National University of Kyiv. Geology, 1, 89-92. 
https://doi.org/10.17721/1728-2713.80.09

17. Hang, Q. (2016). A computationally efficient method for vector autoregression with mixed frequency data. Journal of Econometrics, (193), 433-437.

18. Fomichov, V., Pochepov, V., Sotskov, V., \& Mamaikin, O. (2018).Formation of a calculation model determining optimal rate of stoping face movement with a large deformation of a rock massif. Journal of Engineering and Applied Sciences, 13(7), 2381-2389.

19. Bondarenko, V., Cherniak, V., Cawood, F., \& Chervatiuk, V. (2017). Technological safety of sustainable development of coal enterprises. Mining of Mineral Deposits, 11(2), 1-11. https://doi.org/10.15407/mining11.02.001

20. Malashkevych, D., Sotskov V., Medyanyk V. \& Prykhodchenko D. (2018). Integrated Evaluation of the Worked-Out Area Partial Backfill Effect of Stress-Strain State of Coal-Bearing Rock Mass. Solid State Phenomena, (277), 213-220. https://doi.org/10.4028/www.scientific.net/ssp.277.213 